\title{
From Prison Bars to Society and Return: Some Reflections on an Italian Experience
}

\author{
Eleonora Venneri \\ Assistant Professor of Sociology \\ Department of Law, Economics and Sociology \\ University "Magna Graecia" \\ Catanzaro, 88100, Italy
}

\begin{abstract}
The construction of educational and professional growth paths during the period of detention represents a fundamental tool for promoting the personality of the sentenced person with a view to social reintegration. In Italy, the resources investment in implementation of didactic and cultural pathways implemented by the institution of University Penitentiary Poles (UPP), pursues a clear and innovative emancipatory intent which, against the mere painful, correctional and containing conception of the prison sentence, offers a plausible opportunity of ransom and recovery for restrained people. Starting from a theoretical reflection on the value of education as a vector of inclusion and social integration, this contribution aims to illustrate the current territorial configuration of UPPs, highlighting, at the same time, their favorable outcome and eventual critical issues.
\end{abstract}

Keywords: inclusive education, prison learning, right to study, social integration, university training

\section{Introduction}

Social integration is believed to be one of the positive outcomes of inclusive education patterns. Paraphrasing Edmund Misson (2008), levels of education are a major predictor of a range of later social and economic outcomes so that education and training providers have great potential in promoting social inclusion. This means not only that formation may provide excellent educational outcomes, but also acting as core through where person come into contact with the wider community and a broader range of supports.

In parallel, the dedicated literature suggests a close link between inclusive education and social integration and requires a careful conceptualization of terms whose complexity and semantic opacity risks trivializing their meaning. If, in fact, on the one hand, inclusive education is increasingly understood as a right that entails a series of actions in order to be fulfilled, on the other social inclusion is a very extensive concept that comprise different indicators of sociability and, at operative level, requires the construction of several related variables. For example, the so-called 'ecological approach to social inclusion' (Simplican et al., 2015) intercept individual, interpersonal, organizational, community and sociopolitical variables that influence interpersonal relationships and people participation to social community. In same manner, inclusive education remains a "problematic" topic as understood in different ways, according to theoretical background and national contexts (Meijer and Watkins, 2016). Despite languages pattern changements, discriminatory approaches are still in place, although they are termed inclusive (Slee, 2003; Allan, 2006).

Yet, among these, it is plausible to trace a common denominator. For the purposes of this paper we think, in particular, around of rights. If inclusive education is to be understood as a human right, a principle that values all learners' wellbeing, a means for realizing other human rights and a process for eliminating barriers (so that - as stated CRPD in 2016 - recognition of inclusion is the key to achieving the right to education), in the same way social inclusion is a series of complex interactions between environmental factors and personal characteristics that really provide: rights and opportunities to access public goods and services; a social network within which one receives support; the acknowledgement of individual right to perform social roles in the community.

Among the institutions that conceive social inclusion as proactive vehicle of access of all members of society to highquality services (health, education, justice), the academical one assume a crucial role and, with particular reference to the relationship with penitentiary reality, even more important.

And it is from the awareness of this mission that the title of this contribution derives. From prison bars to society (and return) wants to indicate precisely a "virtuous" circularity in which the promotion of the rights of the prisoner coincides with the exit from a condition of marginality that is sustained by a social opportunity for resocialization and reintegration. 
However, the sense of education in a prison context lies not in the punitive imposition of inflictive rules or models of behavior (which would end up distorting the educational relationship and would have opposite effects) but, rather, in the orientation towards recovery and development of potential of convicts and of their ability to "look outside", structuring conscious citizenship paths. In the same way, the self-referentiality of the university institution gives way to "open" educational scenarios in which to experiment in a tolerant and democratic sense training courses, attributing to knowledge the value of a social experience. As it is known, the dimension of "reciprocity" underlies the educational action inspired by "re-adaptation" of training opportunities to unexpected or tacit needs of the student: "behind bars", the bi-directional educational paths go further the acquisition and development of "basic" skills, but opens to "transversal" processes of self-education, self-orientation and reorganization of personal conscience urging the subject who learns to renew the idea he has of himself and to discover himself an actor and builder of new redemption opportunities.

\section{Beyond of "paper right" to study: the purpose of the UPPS}

Following the stipulation of protocols of understanding between the Ministerial Department of Prison Administration (DAP), the Regional Prison Directors of the Prison Administration (PRAP) and the Italian territorial university locations, the National Conference of Penitentiary University Poles, established in April 2018 at CRUI (Conference of Italian University Rectors), has started a profitable comparison work on the conditions in which the commitments for a "new culture of punishment" they develop, highlighting some needs and defining the minimum requirements they can allow for to set up a structural and functional network of poles for prison teaching. The Conference itself - as foreseen in its Statute - carries out promotional and reflection activities and address of the national university system and of the individual universities regarding the guarantee of the right to the university study of persons detained, in external criminal execution or subjected to the execution of prison security measures. The commitment is that of developing guidelines which, starting from the good practices tested in each of the experiences developed, define adult education in the prevention and punishment institutions as indispensable element of rehabilitation program and provide particular indications aimed at enhancing the specificity of the education trails within the prison institutions. Effectively, the institution of university poles in prison may be represents an adequate intervention measure for the implementation of policies aimed at affirming a new culture of punishment and, for this purpose, reflects the interplay between at least two factors. The first one responds to the need to affirm the prisoner's opportunity to really (and not only "on paper") enjoy the right to study as permanent and indispensable right of the person, with a view to a process of knowledge and awareness that accompanies the subject throughout his existence. The second factor is related not only to a concrete possibility of retrieval for the prisoner but to the definitive overcoming of the socio-cultural conception that identifies the convict with the committed offense. In this perspective, the role assigned to the UPPs is functional not only to the shrewd and ever-growing awareness of the social responsibilities that university institutions are called to support at educational/training, cultural and civil levels (matching themselves critically and without prejudices with the reality of the prison context), but also to the resolute pursuit of the goals of empowering the detained person through a full reaffirmation of personality, identity and self-esteem. So, the "partial" perception of the university institution, limited to research and teaching, gives way to a vision that amplifies the original and peculiar function of universities as a medium for inclusion and social promotion (in this regard, it should not be forgotten that the so-called Third Mission of the university includes forms of public engagement). Not infrequently, in fact, the convict chooses a course of university study not only to give a different meaning to the "time of detention" but to reflect on their own life, offering to himself a real chance of a dignified ransom. In some ways, higher education seems to facilitate the placement of the inmate in a different and alternative dimension to the restriction: training creates social relationships, socially repositions the student and expands, beyond the boundaries of prison, the possibility for the person to enlarge the previous cultural and social capital.

\section{The current scenario}

The UPPs represent an expanding and constant improving phenomenon. As evidenced by the XV report on conditions of detention, prepared by the Antigone association in May 2019, the National Conference of Penitentiary University Poles currently groups 30 universities that are present, with varying degrees of intensity in relation to the number of students and didactic activities carried out, in 70 penitentiary institutions. Despite the shortage in some regions, the distribution on the territory of universities in prisons is quite wide: penitentiary university poles, or in any case, agreements aimed at promoting university studies are current present in: Lazio, Sardinia, Abruzzo, Veneto, Piedmont, Liguria, Tuscany, Umbria, Calabria, Marche, Emilia Romagna, Puglia and Lombardy. About 800 students are enrolled. The mainly chosen courses of study are divided into the disciplines of the political-sociological, humanistic, legal, scientific-natural, agri-food areas. 
Even if there are some limits due to structural and logistic conditions that are difficult to overcome (for example highly specialized laboratories or traineeships), the academic institution shows a growing and specific attention to the prison context and its problems, exercising an important critical, reflective and heterodirect role on the punishment and on the institutions that manage it.

Central, in this regard, are some recurring themes in the reflections on the typicality of adult learning and training. Firstly, the enhancement and implementation of the "native capital" of resources, that the learner has per se, are necessary for the "success" of training: curiosity, suggestions, ideas and, above all, the motivations that push the individual to formation, serve to outline the course of the educational process that exclude absolutisms or mechanical routines. Consistent with the assumption that the acquisition, learning and organization of knowledge are not attributable to "speculative" exercises, but represent tools for a progressive definition of experience in the light of "open" and "flexible" conceptual categories, this reflective modality of education is necessarily related to the level of prisoner motivation and autonomy for learning, and cannot be separated from the transaction and negotiation processes of the activities undertaken for this purpose.

Furthermore, convict's knowledge is rooted in his personal history and in that of the community to which he belongs. Any change, determined by learning, needs to be placed in a perspective of meaning with respect to this dimension. Finally, the task of the training action in prison is to support the full implementation of the adult's need for selffulfillment and to encourage the removal of any obstacles to critical reflection on knowledge and the capitalization of his previous experiences. If one considers that learning is an active, aware, self-regulated and "sensitive" process to the conditions put in place to promote it, one cannot overlook the fact that the impulse to learn arises from the determination of a kind of transfer between one's existential needs and the state of detention. That is, the individual perceives the need to change their behavior to intervene in reality in different forms, such to be modified and brought to meet specific requests. In practice, the inmate who learns excludes considerations of "species" or "genus": it is primarily a person. For this reason, it requires a "holistic" regard effectively aimed at the prompt and accurate consideration of all the complex and multi-dimensional subjective variables that govern the effectiveness and efficiency of the training intervention.

\section{Conclusion}

Presently, the National Conference of Penitentiary University Poles asks the Rectors of Italian Universities to agree on certain qualifying commitment segments in penitential institutions: extend the network of University Poles with the involvement of universities not currently engaged to offer opportunities to detained students (ensuring at least one pole per Region); commitment to find the resources necessary for the operation of the poles; accompany and support with studies, training initiatives and consultancy for the associative realities of third sector, voluntary work and institutions that operate in various ways in prison; contribute, through cultural initiatives for prisoners, even those not enrolled in university, to their growth and to the possibility of understanding different aspects of society, science and culture, allowing them to keep "a window on the world" open. In the awareness that, in the face of "suspended rights", the educational action of the University in prison can and must develop not only with the aim of obtaining a prison formally compliant with regulations protecting the rights of "guests" but above all by advancing in the promotion of a global development of the detained person, promoting their conscious self-determination and the effective execution of the fundamental rights on which every possibility of social reintegration is founded.

The specific "relational" dimension of an educational model of this type, free from "indoctrination" or pseudo-usercentered attitudes and, as such, characterized by the mutual conditioning of predefined roles and behaviors (the teacher as "expert" - the student who "asks for help") and from the presentation of contents that are not interpreted but transmitted "fideistically", really assigns a procedural, intersubjective value to the training, concretely oriented towards the change and creativity of the two protagonists: the teacher who, in function of each specific situation, it "problematically" builds contents; the student who offers himself "dialectically" and to the best of his wealth and potential. In the consciousness that: «Learning is facilitated when the student participates responsibly in the learning process. Learning which involves the whole person of the learner is the most lasting and pervasive. Independence, creativity and self-reliance are all facilitated when evaluation by others is of secondary importance. The most socially useful learning in the modern world is the learning of the process of learning, a continuing openness to experience" (Rogers, 1969: 114).

\section{Acknowledgement}

The research is financed by Ministerial fund for the financing of basic research activities (FFABR) 


\section{References}

Allan, J. (2006). The repetition of exclusion. International Journal of Inclusive Education, 10 (2-3), 121-133. https://doi.org/10.1080/13603110500221511

Meijer, C., \& Watkins, A. (2016). Changing Conceptions of Inclusion Underpinning Education Policy. In A. Watkins, C. Meijer (Eds.), Implementing Inclusive Education: Issues in Bridging the Policy-Practice Gap, International Perspectives on Inclusive Education. (Vol. 8). Bingley: Emerald Group Publishing Limited. https://doi.org/10.1108/S1479-363620160000008023

Misson, E. (2008). Inclusion through education. In Social Inclusion and Youth Workshop Proceedings. Metropole Conference Centre in Fitzroy, Victoria, 30th of October 2008. Victoria: Brotherhood of St Laurence.

Prina, F. (2019). Il diritto dei detenuti agli studi universitari: l'esperienza dei Poli universitari penitenziari in Italia. Roma: Antigone.

Rogers, C. R. (1969). Freedom to learn: a view of what education might become. Columbus: Charles E. Merrill.

Slee, R. (2003). Teacher Education, Government and Inclusive Schooling: The Politics of the Faustian Waltz. In J. Allan (Ed.), Inclusion, Participation and Democracy: What is the Purpose?. Inclusive Education: Cross Cultural Perspectives, vol 2 (pp. 207-223). Dordrecht: Springer. https://doi.org/10.1007/0-306-48078-6_13

Simplican, S. C., Leader, G., Kosciulek, J., \& Leahy, M. (2015). Defining social inclusion of people with intellectual and developmental disabilities: an ecological model of social networks and community participation, Research in Developmental Disabilities, 38, 18-29. https://doi.org/10.1016/j.ridd.2014.10.008

UN Committee on the Rights of Persons with Disabilities (CRPD) (2016). General comment No. 4 (2016). Article 24: Right to inclusive education, 2 September 2016, CRPD/C/GC/4.

https://www.refworld.org/docid/57c977e34.html 